Acta Sci. Pol. Technol. Aliment. 19(3) 2020, 347-357

pISSN 1644-0730

eISSN 1898-9594

http://dx.doi.org/10.17306/J.AFS.2020.0850

ORIGINAL PAPER

Received: 2.07 .2020

Accepted: 25.08 .2020

\title{
CHARACTERIZATION OF PECTIN EXTRACTED UNDER MILD CONDITIONS FROM TEMPESQUISTLE (SIDEROXYLON PALMERI) FRUIT AT TWO MATURITY STAGES
}

\author{
Jessica Sofía Ayala-López ${ }^{1}$, Víctor Inocencio Pacheco-Contreras ${ }^{1}$, \\ Norma Francenia Santos-Sánchez², Beatriz Hernández-Carlos², \\ Gabriela F. Lara-Ruiz², Raúl Salas-Coronado² \\ ${ }^{1}$ Unidad Tecnológica, Instituto Tecnológico Superior de Acatlán de Osorio \\ Carretera Acatlán-San Juan Ixcaquixtla, km 5.5, CP 74949, Acatlán de Osorio, Puebla, México \\ ${ }^{2}$ Instituto de Agroindustrias, Universidad Tecnológica de la Mixteca \\ Carretera Huajuapan-Acatlima, km 2.5, CP 69000, Huajuapan de León, Oaxaca, México
}

\begin{abstract}
Tempesquistle tree (Sideroxylon palmeri) belongs to family Sapotaceae, and its fruits contain hydrophilic and hydrophobic gums. Aim of this study was to develop an extraction method for pectin, a hydrophilic gum, from green and ripe tempesquistle fruit. The extraction method was gentle to minimize potential structural changes in pectin, a maceration was used, and then pectin precipitation was induced with acetone at room temperature. Pectin characterization was carried out in two steps. The first step consisted of qualitative tests of Molisch, Fehling and Lugol. The second step consisted of quantitative tests to determine esterification degree (ED) by ATR-FTIR and D-galacturonic acid (D-GalA) content with a colorimetric assay. ATR-FTIR spectroscopic method revealed that green and ripe tempesquistle fruit have an ED of $0 \%$ and $30.4 \%$, respectively. Both fruit have a low ED pectin. The content of D-GalA in green and ripe pectins was $18.8 \pm 2.7 \%$ and $20.2 \pm 0.6 \%$, respectively. The yield obtained in green and ripe fruit samples was $1.6 \pm 0.2 \%$ and $3.0 \pm 0.1 \%$, respectively. The extraction method allowed two types of pectins obtained in function of maturity stage of tempesquistle fruit distinguishable by ATR-FTIR.
\end{abstract}

Keywords: Sideroxylon palmeri, mild extraction, esterification degree, ATR-FTIR, D-galacturonic acid, pectin

\section{INTRODUCTION}

Tempesquistle (Sideroxylon palmeri) is a tree native to the Tehuacán-Cuicatlán Valley, México, that has a height of $16 \mathrm{~m}$ and whose fruit are part of the regional diet (Arellanes et al., 2013). People gather tempesquistle fruit in tropical deciduous forests and from their gardens (González-Soberanis and Casas, 2004). There are two $S$. palmeri varieties, one with round fruit and a second with avocado-shaped fruit; both varieties are consumed locally. However, the round fruit variety sells better (Blancas et al., 2013). Tempesquistle fruit are marketed and consumed mainly in green stage, and they are used to prepare marinades, salads and vinaigrettes, among other foodstuffs. The fruit in its mature stage is not used, becoming a residue.

Pectins are widely used as emulsifiers, stabilizers, thickeners and gelling agents (Brejnholt, 2010).

『rsalas@mixteco.utm.mx, phone +52(953)5320-214, ext. 400 
These polymers are important because they are inexpensive, harmless, highly stable and biocompatible gelants. This last characteristic of pectins is of paramount importance in the food, pharmaceutical and cosmetic industries (Ciriminna et al., 2016). Pectins are linear heteropolysaccharides with high molecular weights $(80-400 \mathrm{kDa})$ constituted by three main moieties (Fig. 1; Ciriminna et al., 2017; Harholt et al., 2010). The first moiety is a homogalacturonan (HG) based on $\alpha$-D-galacturonic acid (D-GalA) units linked through $\alpha-(1 \rightarrow 4)$ bonds with a mean chain length of 100 units. HG represents nearly $65 \%$ of the pectin (Wolf et al., 2009). The galacturonan chain may contain monomers with an esterified (C-6) carboxylic group and/or a hydroxyl group (at $O-2 / O-3$ position). The second moiety is a rhamnogalacturonan (RG-I) constructed with units of dimer $\alpha-(1 \rightarrow 4)-\alpha-D-G a l A-$ $-\alpha-(1 \rightarrow 2)-\alpha-L-r h a m n o s e$ with arabinan, galactan and/or arabinogalactan side chains with the carboxyl groups of D-GalA esterified. RG-I represents about $20-35 \%$ of pectin polymer (Mohnen, 2008). A third moiety named RG-II possesses a linear backbone of D-GalA units linked through $\alpha-(1 \rightarrow 4)$ bonds carrying four well-defined oligosaccharide side chains called A, B, C and D and constitute $<10 \%$ of pectin (Alistair and Glyn, 2016; Yapo, 2011). The chemical structure of pectins changes between different fruit and their growth stages (Dimopoulou et al., 2019). Pectins can be esterified with different groups, including methyl groups. These polymers are classified according to their esterification degree (ED) into two types, high $(>50 \% \mathrm{ED})$ and low $(<50 \% \mathrm{ED})$ esterification degrees. The degree and type of esterification varies in different plant species (Wolf et al., 2009). High ED pectins generate gels at low $\mathrm{pH}$, stabilized by hydrophobic interactions, while those with low ED will form gels electrostatically stabilized by metal cations (Alistair and Glyn, 2016).

On the other hand, various studies have shown that during the ripening process of fruit, there is an increase in concentration of pectins (Chea et al., 2019; Paniagua et al., 2017). Furthermore, pectins have important structural changes that favour their solubilization in the medium. One of these structural changes is a decrease in galacturonic acid content (Ghai et al., 2016).

\section{Rhamnogalacturonan II} (RG II)

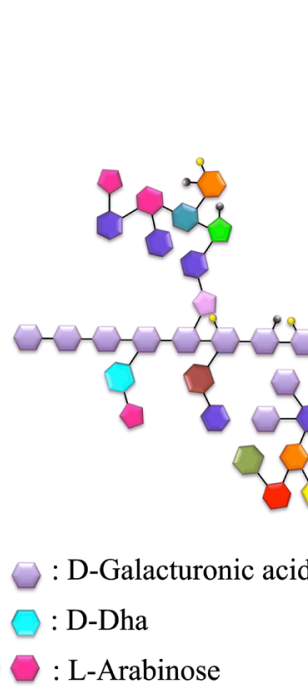

Homogalacturonan (HG)
Rhamnogalacturonan I (RG I)

Fig. 1. General structure of pectins: Kdo - 3-deoxy-D-manno-2-octulosonic acid, Dha - 3-deoxy-D-lyxo-2-heptulosaric acid 
Pectins also have a variety of properties that promote consumer health (Zaitseva et al., 2020). In relation to this matter, Minzanova et al. (2018) carried out a comprehensive review about the pharmacological applications of pectins. The results of this review showed that some of pectin's main applications are as immunoregulators, anti-inflammatories, hypoglycemic agents, antibacterials, antioxidants and anti-tumors. They also identified that these polysaccharides can contribute to improving drug delivery systems. On the other hand, Torkova et al. (2018) carried out a comparative study of anticancer properties of pectin samples from pumpkin, citrus and apple at different concentrations. Pumpkin pectins were obtained from an enzymatic extraction without acid addition. While citrus and apple pectins were commercially obtained from a traditional method that uses an acidic medium with heating. The results of this study showed that pumpkin pectin has greater activity than the others two pectins. Torkova et al. (2018) suggested that the extraction process is a key factor for pectin activity. An extraction without an acid medium contributes to having a pectin with greater anticancer activity than one extracted in a hot acid medium. This is because the acidic medium induces structural changes in pectins during extraction process. In another study, Fan et al. (2020) evaluated the ED effects of pectins on ulcerative colitis in mice. The study results showed that low ED pectins have a greater protective effect in mice with acute colitis than high ED pectins.

The conventional pectin extraction is based on the use of an acidic medium and generally requires $\mathrm{pH} 0.5-2.5$, temperatures of $50-90^{\circ} \mathrm{C}$ and a time of 30-150 min (Jafari et al., 2017). These extraction conditions affect material properties and extraction efficiency (Yapo et al., 2007). For this reason, new extraction methods have been modified or developed to minimize structural changes of pectins, such as ultrasound-assisted extraction (UAE; Sengar et al., 2019), microwave-assisted extraction (MAE; Tongkham et al., 2017), accelerated solvent extraction (ASE; Chawananorasest et al., 2016), and supercritical fluid extraction (SFE; Muñoz-Almagro et al., 2019), among others. In general, these methods can be efficient for pectin extraction without significantly affecting its chemical structure. However, these consume large amounts of energy or are difficult to implement on a commercial scale. Consequently, the search for inexpensive methods without an acidic medium or low temperatures becomes important.

Pectin identification and characterization in fruit extracts involves selecting different chemical assays both qualitative and quantitative. Assays of Molisch (Walia et al., 2013), Fehling (Wang et al., 2019) and Lugol (Colodel et al., 2017) are commonly used to discard free sugars and starches in pectin extracts from fruit. While pectin quantification in extracts is commonly carried out from the ED and D-GalA content, ED determination is performed by an acid-base titration or the areas ratio of carbonyl tension bands of acid and ester groups in infrared (IR) spectra (Fazio et al., 2020; López-Mercado et al., 2018). D-galacturonic acid quantification is usually carried out by colorimetric assays, using 3-carbazole or 3-phenylphenol as chromogenic reagents (Yang et al., 2019; Kanchana et al., 2019).

In the literature, there are no reports of studies related to chemical composition of tempesquistle fruits. For this reason, present study established the objective of obtaining pectin extracts from tempesquistle (S. palmeri) fruit at two stages of maturity (green and ripe) and carry out its characterization. The extraction was done through a water maceration, and pectin recovery was carried out with acetone. Pectin characterization was achieved using chemical methods and attenuated total reflection Fourier transform IR (ATR-FTIR) spectroscopy, and D-GalA quantification was obtained by colorimetric assay based on the 3-phenylphenol reagent.

\section{MATERIALS AND METHODS}

\section{Fruit samples}

The green and ripe tempesquistle fruits of a round variety and free from physical damage were collected in San Jerónimo Xayacatlán, Puebla, México [longitude (dec): -97.893611 and latitude (dec): 18.201944] in 2018. The fruits were selected based on their color, green fruit showed an avocado green color and ripe fruit showed a brown color, both in more than 95\% of their surface. The fruits were washed with soap and water, then rinsed with water, dried and weighed. The fruits were stored in airtight plastic containers at 
$4^{\circ} \mathrm{C}$ prior to pectin extraction for a period not exceeding 15 days.

\section{Pectin extraction}

The seeds of $260 \mathrm{~g}$ tempesquistle fruits were removed and the pulp was ground in a homemade blender with $500 \mathrm{~mL}$ of water. The liquefied pulp was macerated for $3 \mathrm{~h}$ with constant agitation. Then, sample was filtered through a cloth, and filtrate was subjected to two new consecutive filtrations, first through a Whatman ${ }^{\circledR}$ \#1 paper filter and after through a Whatman ${ }^{\circledR} \# 2$ paper filter. Filtrate was evaporated to around $30 \%$ of its original volume by rotatory evaporation at $47^{\circ} \mathrm{C}$ under reduced pressure. The residue was mixed with acetone at a 1:2 ratio (residue filtrate/acetone) to induce pectin precipitation. Subsequently, the mixture was filtered through a Whatman ${ }^{\circledR} \# 2$ paper filter. Once the solids were retained, they were washed with $20 \mathrm{~mL}$ of acetone to remove water. The solids were dried at room temperature and were weighed to determine yields. Finally, the dried extracts were stored at room temperature until their characterization.

\section{Chemical methods for carbohydrate identification Molisch's assay}

$5.0 \mathrm{mg}$ of dry extract from green fruit sample and $5.0 \mathrm{mg}$ of dry extract from ripe fruit sample were placed in different vials. Later, $1 \mathrm{~mL}$ of water was added to each vial and 1 drop of $15 \%(\mathrm{w} / \mathrm{w}) \alpha$-naphthol solution in ethanol (Patil et al., 2018). 1-2 mL of concentrated $\mathrm{H}_{2} \mathrm{SO}_{4}$ was then added slowly to vials and mix was constantly shaken. D-glucose and D-fructose were used as positive test controls. A purple or blue colored solution indicated presence of carbohydrates.

\section{Fehling's assay}

$5 \mathrm{~mL}$ Fehling's I solution and $5 \mathrm{~mL}$ of Fehling's II solution were mixed (Fehling's reagent), and two experiment groups were created. The first group consisted of mixing Fehling's reagent with the control samples and dry extracts from the tempesquistle fruit. While in the second experiment group, concentrated hydrochloric acid was added for the hydrolysis of disaccharides and polysaccharides and then Fehling's reagent was added. Both experiment groups started with preparation by separating $5 \mathrm{mg}$ of D-glucose, D-fructose, sucrose, and dry extracts of green and ripe tempesquistle dissolved in $5.0 \mathrm{~mL}$ of water. In the first group of experiments, mixture was held in a water bath at a temperature of $70-80^{\circ} \mathrm{C}$ with constant stirring for $10 \mathrm{~min}$ and then $1 \mathrm{~mL}$ of Fehling reagent was added slowly. The mixture was held in the hot water bath for 5 additional minutes. The presence of reducing sugars in sample was confirmed with a color change from blue to orange and an orange-reddish precipitate. In the second group of experiments, one drop of concentrated $\mathrm{HCl}$ was slowly added to samples in aqueous solution. Finally, the procedure applied to the first experiment group was utilized in the second experiment group (Sundarraj and Ranganathan, 2017).

\section{Lugol's assay}

Solutions of $10 \mathrm{mg}$ of D-glucose, starch, and dry extract of green and ripe tempesquistle fruit, and $1 \mathrm{~mL}$ of water were prepared. Then, 1 drop of Lugol solution, prepared from $0.5 \mathrm{~g}$ of $\mathrm{I}_{2}$ and $1.0 \mathrm{~g}$ of LiI in $8.5 \mathrm{~mL}$ of water, was added to each sample and the reaction mixture was stirred. A black solution and precipitate indicated the presence of starch (Martín-Sánchez et al., 2013).

\section{Esterification degree (ED) determination by ATR-FTIR}

The sample preparation was performed based on the modified method reported by Wrolstad et al. (2005). A mixture of $0.2 \mathrm{~g}$ of sample [tempesquistle dry extract from green or ripe fruit, or commercial pectin (Ma Baker and Chef brand)] and $5 \mathrm{~mL}$ of $70 \%$ aqueous propan-2-ol acidified with $0.5 \mathrm{~mL}$ of $0.8 \mathrm{M} \mathrm{HCl}$ solution was stirred for $15 \mathrm{~min}$. It was then filtered through a previously weighed fiberglass filter and washed three times with $10 \mathrm{~mL}$ portions of $70 \%$ aqueous propan2-ol, until the filtrate was free of chlorides. The chloride test consisted of transferring $5.0 \mathrm{~mL}$ of filtrate to a test tube, and then $0.3 \mathrm{~mL}$ of $3 \mathrm{M} \mathrm{HNO}_{3}$ and a few drops of $\mathrm{AgNO}_{3}$ were added. After this, $0.3 \mathrm{~mL}$ of $3 \mathrm{M}$ $\mathrm{HNO}_{3}$ were added to make the solution more acidic and help precipitate silver chloride. It should be noted that a chloride-free filtrate implies a crystalline solution; otherwise $\mathrm{AgCl}$ precipitate forms. This test shows total removal of chlorides in residue from washes with $70 \%$ aqueous propan-2-ol. Once the removal of chlorides was assured, the residues were washed with 5.0 $\mathrm{mL}$ of propan-2-ol to remove any water present in 
residue, and the fiberglass filter with the washed sample was placed in a drying oven at $105^{\circ} \mathrm{C}$ for $2.5 \mathrm{~h}$. After this time, the sample was placed in a desiccator. This sample was used to acquire IR spectra in an FTIR spectrophotometer model Alpha Platinum-ATR (Bruker Optik, $\mathrm{GmbH}$ ) with an attenuated total reflectance module (ATR). The spectrophotometer was equipped with a deuterated triglycine sulfate detector (DTGS) and a diamond sample holder with a $45^{\circ}$ parallelogram geometry. $100 \mathrm{mg}$ of the treated sample were placed in the holder, and pressed to achieve better contact with the crystal surface. For each sample, spectra were obtained at room temperature with 70 scans, at a resolution of $4 \mathrm{~cm}^{-1}$ in the spectral region of $4000-400 \mathrm{~cm}^{-1}$. The IR spectra were processed with Opus software. The intensity was expressed in absorbance units. Spectrum obtained was compared with the characteristic bands of pectin, specifically two bands. These correspond to the carbonyl stretch bands $(\mathrm{C}=\mathrm{O})$ of carboxylic acid at $1630-1600 \mathrm{~cm}^{-1}$ and carboxylic esters at $1730 \mathrm{~cm}^{-1}$. These bands were used to determine the esterification degree (ED) using a ratio of areas under a curve corresponding to acid and ester groups, applying formula reported by Rascón-Chu et al. (2016).

\section{D-galacturonic acid (D-GalA) quantification}

This test was performed based on the modified method reported by Wrolstad et al. (2005). $10 \mathrm{mg}$ of sample were placed in an ultrasound bath at $4^{\circ} \mathrm{C}$. Then, $1 \mathrm{~mL}$ of concentrated $\mathrm{H}_{2} \mathrm{SO}_{4}$ was slowly added to the sample. This mixture was kept in an ice bath with ultrasound for $10 \mathrm{~min}$ to promote dissolution of the sample. After this time, $1 \mathrm{~mL}$ of concentrated $\mathrm{H}_{2} \mathrm{SO}_{4}$ was added to mixture and subsequently sonicated at $50 \mathrm{~W}$ until sample dissolved completely. A blank was prepared by adding $2 \mathrm{~mL}$ of concentrated $\mathrm{H}_{2} \mathrm{SO}_{4}$ to this in a vial. Then, slowly, $0.5 \mathrm{~mL}$ of previously degassed type I water was added to blank and sample, and the mixture was again sonicated for $5 \mathrm{~min}$ at $4{ }^{\circ} \mathrm{C}$. The $\mathrm{H}_{2} \mathrm{SO}_{4}$ used in all the previous steps should be in an ice bath at approximately $10^{\circ} \mathrm{C}$. Once the samples and blank were prepared, dilutions were made with water. For commercial pectin (Ma Baker and Chef brand) and its blank, 1:10 dilutions were prepared, while for the samples of green and ripe tempesquistle fruit and their blanks, the dilutions were 1:8. These dilutions were stirred carefully in an ice bath. The evaluation of each sample was carried out in triplicate. The diluted samples were stable during approximately $12 \mathrm{~h}$ of storage at temperatures from 4 to $10^{\circ} \mathrm{C}$. To perform the colorimetric reaction, $400 \mu \mathrm{L}$ aliquot of standard or sample was mixed with $40 \mu \mathrm{L}$ of sulfamic acid/ potassium sulfamate solution ( $\mathrm{pH} 1.6)$. Then, $2.4 \mathrm{~mL}$ of $75 \mathrm{mM}$ sodium borate solution was added at $10^{\circ} \mathrm{C}$. These reaction mixtures were removed from the cold bath and were placed in a hot water bath $\left(80-85^{\circ} \mathrm{C}\right)$ for $20 \mathrm{~min}$ and stirred, then cooled in an ice bath at $10^{\circ} \mathrm{C}$ for $10 \mathrm{~min}$. After this time, the reaction mixtures were removed from the cold bath and the samples were added to $80 \mu \mathrm{L}$ of the 3-phenylphenol solution, while the blanks were added to $80 \mu \mathrm{L}$ of $0.5 \% \mathrm{NaOH}$ and stirred. These last two steps had to be performed in a time interval of 10 to $30 \mathrm{~min}$ to minimize changes in the reaction mixtures and avoid variations in absorbance. $150 \mu \mathrm{L}$ of the reaction mixture was transferred to a microplate, and shaken for $1 \mathrm{~min}$ at room temperature. Then, absorbance was measured at $515 \mathrm{~nm}$ in a microplate reader spectrophotometer (ELX808, BioTek). Sample, standard and blank measurements were performed in triplicate. D-GalA was used as a standard for the calibration curve at concentrations of $45.1,90.2,135.3$ and $180.4 \mu \mathrm{g} \cdot \mathrm{mL}^{-1}$.

\section{RESULTS AND DISCUSSION}

\section{Pectin extraction from green and ripe tempesquistle fruit}

The color of green tempesquistle fruit extract was similar to that of commercial pectins. However, dry extract from the ripe fruit showed a brown coloration. The brown color of ripe fruit extract is possibly due to a co-precipitation of pigments present in this fruit (Fig. 2). It should be mentioned that when dry extract was dissolved in water, the color of solution turned a faint yellow. The extraction yields obtained from extracts of green and ripe tempesquistle fruit on a dry basis were $1.6 \pm 0.2 \%$ and $3.0 \pm 0.1 \%$, respectively (Table 1). Compared to literature data, pectin yields from the green fruit were similar to values reported for pectin extracted from green papaya (Vasconcella weberbave$r i$ ), which has an extraction yield of $1.0 \%$. The extraction yield of the ripe fruit is similar to the extraction yield of apple pectin: $3.1 \%$ (Maldonado-Culquimboz et al., 2010). 


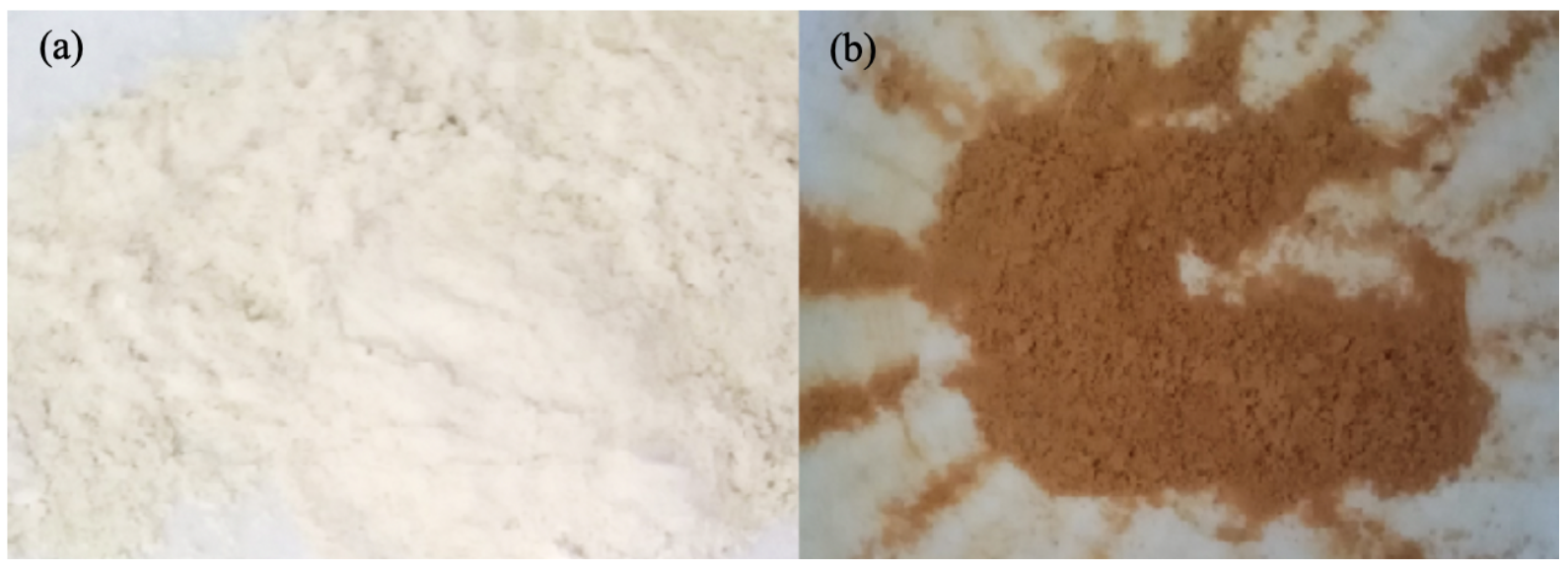

Fig. 2. Powders of extract from green (a) and ripe (b) tempesquistle (Sideroxylon palmeri) fruit

Table 1. Pectin extraction yield, esterification degree (ED) and D-galacturonic acid (D-GalA) content, \%

\begin{tabular}{lccc}
\hline \multicolumn{1}{c}{ Sample } & $\begin{array}{c}\text { Yield on wet } \\
\text { basis }\end{array}$ & ED & D-GalA \\
\hline Commercial & NR & $64.9 \pm 1.2$ & $63.88 \pm 0.67$ \\
Green fruit & $1.6 \pm 0.2$ & 0 & $18.86 \pm 2.41$ \\
Ripe fruit & $3.0 \pm 0.2$ & $30.4 \pm 0.8$ & $20.23 \pm 0.28$ \\
\hline
\end{tabular}

Mean \pm standard deviation, $n=3$. These values were calculated in Microsoft Excel version 16.40.

$\mathrm{NR}$ - no reported.

\section{Carbohydrate identification}

Molisch's assay allowed carbohydrates to be identified in both samples of powders from the green and ripe fruit. Fehling test is an indicator for reducing groups such as aldehydes. This reaction allows differentiation between reducing and non-reducing sugars. In the reaction, the aldehyde group of the reducing sugar is oxidized by $\mathrm{Cu}^{2+}$ ions to form carboxylic acids. The $\mathrm{Cu}^{2+}$ of tartrate complex is reduced and converted into cuprous oxide $\left(\mathrm{Cu}_{2} \mathrm{O}\right)$ that precipitates forming a reddish solid, which is distinctive of a positive Fehling's assay with reducing sugars. Three controls, D-glucose, D-fructose and sucrose, were used to evaluate the presence of reducing sugars in ripe and green fruit extracts. This assay was divided into two experiment groups, the first experiment group involved a mixture of controls or samples with Fehling's reagent, and the second experiment group consisted of first adding $\mathrm{HCl}$ to solutions containing controls or samples and subsequently adding Fehling's reagent. The second experiment group had the purpose of identifying hydrolysis products present in samples. In this experiment, sucrose, a non-reducing sugar, was useful because in acid medium hydrolyses and leads to a positive result in Fehling's assay.

The ripe fruit extract reacted with Fehling's reagent, while green fruit extract did not. This result can be explained due to ripe fruit extracts having sugars as part of their ripening process. These simple sugars are co-extracted from the fruit along with pectin.

When sucrose is first exposed to an acidic medium and then reacts with Fehling's reagent, reaction occurs. This is due to glycosidic bond in sucrose being cleaved by hydrolysis in an acidic medium, and D-glucose and D-fructose being released in the reaction medium. Glycosidic bond hydrolysis in the acidic medium was also carried out in extracts of green and ripe fruit with purpose of identifying the nature of saccharides units. The results indicate that both green and ripe fruit extracts that underwent to hydrolysis process contain polysaccharides with reducing sugars units.

\section{Lugol's assay}

Lugol's assay is used to identify presence of starch in a sample. The first stage consists of $\mathrm{I}_{2}$ reacting with $\mathrm{KI}$ to form $\mathrm{KI}_{3}$. Subsequently, this reagent is mixed with sample to promote a complexation reaction between triiodide and starch. When sample contains starch, 
a mixture of this with Lugol's reagent turns a blue-violet color. The color change produced by Lugol's reagent is due to triiodide inducing starch molecules to be organized in form of whorls around the triiodide. This complex is an inclusion compound that modifies physical properties of molecule, creating a blue-violet color (Martín-Sánchez et al., 2013). In the present study, LiI was used instead of KI and a different result was obtained than those expected in Lugol's assay, because $\mathrm{Li}^{+}$cation induces a strong triiodide-starch inclusion complex precipitation and solution turns black. Lugol's assay was applied to tempesquistle fruit extracts, and controls, D-glucose (negative control) and starch (positive control). The only sample that presented a positive reaction to Lugol assay's was starch solution, creating an insoluble black precipitate. Therefore, it was concluded that both tempesquistle fruit extracts do not contain starches.

\section{D-galacturonic acid (D-GalA)}

Pectins consist mainly of D-GalA units, and these units are generally in form of salts, acids or esters, including methyl esters. Therefore, D-GalA percentage in extracts from green and ripe tempesquistle fruit was evaluated. D-GalA quantification was carried out using the spectrophotometric method that involves the formation of a D-GalA-3-phenylphenol complex that absorbs at $515 \mathrm{~nm}$. The method is highly sensitive and allows specific quantification of D-GalA at concentrations in a range from 45 to $180 \mathrm{ppm}$. The results obtained helped to unequivocally establish the presence of pectin in extracts of green and ripe tempesquistle fruit, as well as difference in chemical composition that occurs between these two samples and a commercial sample of citrus pectin used as a positive control.

The extracts of green and ripe tempesquistle fruit showed similar concentrations of D-GalA, 18.86 \pm 2.41 and $20.23 \pm 0.28 \%(\mathrm{w} / \mathrm{w})$, respectively. However, these concentrations are different in respect to concentrations obtained for commercial pectin samples $[63.88 \pm 0.67 \%(\mathrm{w} / \mathrm{w})]$. This result can be attributed to the pectin source and the extraction conditions (Masmoudi et al., 2012). Additionally, the pectin structure is not only composed of D-GalA, but other sugars are also found, such as D-arabinose, D-glucose and D-rhamnose (Mendoza-Vargas et al., 2017). The extracts of green and ripe tempesquistle fruit showed a positive reaction to Molish's assay, which allows carbohydrates presence to be identified in samples. Also, the extract from ripe tempesquistle fruit tested positive for Fehling's assay without acid addition. Therefore, this extract contains free reducing sugars.

Rascón-Chu et al. (2016) quantified the monosaccharides in apple pectin samples and found D-galactose, D-xylose, D-rhamnose, D-arabinose and D-glucose with values of 34.04, 0.31, 2.61, 3.01 and $1.49 \mathrm{~g} \cdot 100 \mathrm{~g}^{-1}$ of sample, respectively. FTIR-ATR spectrum of the extract from green tempesquistle fruit showed an overlapping band with an acid band of around $1530 \mathrm{~cm}^{-1}$ (Fig. 3). This infrared band was reported by Pawar et al. (2018) and Urias-Orona et al. (2010) for pectins that contain monosaccharide units in their structure such as D-galactose, D-xylose, D-glucose, D-arabinose, D-rhamnose, among others. It is worth mentioning that the sample reported by Urias-Orona et al. (2010) contains monosaccharides in pectin structure from chickpeas. These monosaccharides are D-arabinose, D-galactose, D-glucose, D-xylose, D-mannose and D-rhamnose with values of 7.7, 12.3, $1.6,0.4,0.6$ and $10.4 \mathrm{~g} \cdot 100 \mathrm{~g}^{-1}$ of sample, respectively. Additionally, Pawar et al. (2018) found monosaccharides in pectin samples obtained from Cordia dichotoma fruit. It is also possible to affirm that extracts of tempesquistle fruit could contain secondary metabolites, mainly phenolic compounds (Mendoza-Vargas et al., 2017). Rascón-Chu et al. (2016) suggest that phenols found in apple pectin samples could have been co-extracted because the phenolic compounds are found throughout the fruit. The authors reported that pectin samples extracted from apples contain $0.947 \mathrm{~g}$ of total phenols $\times 100 \mathrm{~g}^{-1}$ of sample. It should be noted that a preliminary colorimetric test was performed for qualitative identification of phenolic compounds using the Folin-Ciocalteu Reagent. This test was positive for both extracts of green and ripe tempesquistle fruit. A solution of $50 \mathrm{ppm}$ of gallic acid was used as a positive control. Some phenolic compounds that could be part of the extract's composition are catechins, anthocyanins and tannins, which could have co-precipitated together with pectin causing a brown color to the extracts (Mendoza-Vargas et al., 2017). This effect could be attributed to extract of ripe tempesquistle fruit, since dry extract has a brown color. 
The D-galacturonic acid content data in the extracts of green and ripe tempesquistle fruit were similar to the values reported for green and ripe mountain papaya, 27 and 26\%, respectively (Maldonado-Culquimboz et al., 2010).

\section{Esterification degree (ED)}

ED determination of samples was carried out from the infrared spectra of solid state samples and an integration of the areas under curve of bands corresponding to carboxylic acid $\left(1730 \mathrm{~cm}^{-1}\right)$ and carboxylic ester (1630-1600 $\left.\mathrm{cm}^{-1}\right)$ groups. Pectin's ED is important since this value determines its main classification and its potential uses in the food industry. The determines relative amount of D-GalA esterified in pectin. In this assay, $\mathrm{pH}$ and delay temperature must be controlled in process; since it was observed that a minimum of variation in these two variables triggers changes in results. The results of ED quantification showed that the two stages of fruit ripeness lead to different ED. The Pectin's ED from ripe tempesquistle fruit calculated by ATR-FTIR was $30.4 \pm 0.8 \%$, indicating that it is a fruit with pectin of a low ED (Fig. 3). In the case of green tempesquistle fruit sample, esterification was not found (Fig. 3). This indicates that the extract from green tempesquistle fruit predominantly contains pectic acids. In the test, a commercial sample with an ED of $67-71 \%$ was selected as a positive control. In the latter case, it is confirmed that the results obtained are consistent with those reported by the product manufacturer (Table 1, Fig. 3).
The extract of ripe tempesquistle fruit showed an ED of $30.4 \pm 0.8 \%$, similar to reported for apple peel, $33.44 \pm 0.04 \%$ (Virk and Sogui, 2004). It should be noted that after performing a thorough literature review about fruit rich in pectic acids, reports were not found.

\section{CONCLUSIONS}

Pectin extracts from green and ripe tempesquistle fruit were obtained with yields of $1.6 \pm 0.2 \%$ and 3.0 $\pm 0.1 \%$, respectively. Pectin from the extract of green fruit is essentially pectic acid; while the extract of the ripe fruit contains pectin of a low ED, $30.4 \%$, according to FTIR-ATR data. On the other hand, the quantification of D-galacturonic acid made it possible to establish that pectins present in tempesquistle fruit extracts are at around $20 \%$. The extracts could contain chemical compounds that were co-extracted during the stage of obtaining pectins, and such compounds may be phenols and terpenes. Also, a high monosaccharide content in the pectins structure obtained from tempesquistle fruits is possible, mainly in the extract of ripe fruit. Finally, it is important to highlight that this is the first study in which chemical composition of tempesquistle fruits has been studied, particularly pectin content.

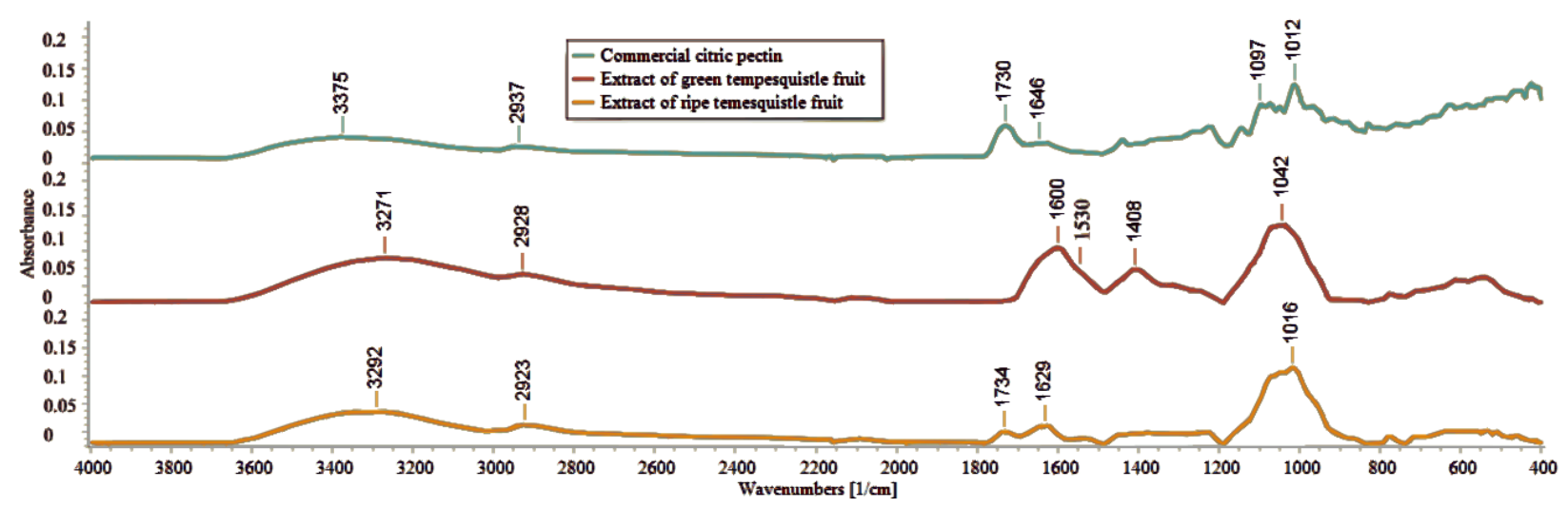

Fig. 3. ATR-FTIR spectra of studied samples 


\section{ACKNOWLEDGMENTS}

The Universidad Tecnológica de la Mixteca and Instituto Tecnológico Superior de Acatlán de Osorio provided support.

\section{REFERENCES}

Alistair, M. S., Glyn, O. P. (2016). Food polysaccharides and their applications. Florida: CRC Press. https://doi. org/10.1201/9781420015164

Arellanes, Y., Casas, A., Arellanes, A., Vega, E., Blancas, J., Vallejo, M., ..., Pérez-Negrón, E. (2013). Influence of traditional markets on plant management in the Tehuacán Valley. J. Ethnobiol. Ethnomed., 9, 38. https:// doi.org/10.1186/1746-4269-9-38

Blancas, J., Casas, A., Pérez-Salicrup, D., Caballero, J., Vega, E. (2013). Ecological and socio-cultural factors influencing plant management in Náhuatl communities of the Tehuacán Valley, Mexico. J. Ethnobiol. Ethnomed., 9, 39. https://doi.org/10.1186/1746-4269-9-39

Brejnholt, S. M. (2010). Pectin. In A. Imeson (Ed.), Food stabilisers, thickeners, and gelling agents (1st ed., pp. 237-265). Ames, IA: Blackwell Publ. https://doi. org/10.1002/9781444314724

Chawananorasest, K., Saengtongdee, P., Kaemchantuek, P. (2016). Extraction and characterization of tamarind (Tamarind indica L.) seed polysaccharides (TSP) from three difference sources. Molecules, 21, 775. https://doi. org/10.3390/molecules21060775

Chea, S., Yu, D. J., Park, J., Oh, H. D., Sun Woo Chung, S. W., Lee, H. J. (2019). Fruit softening correlates with enzymatic and compositional changes in fruit cell wall during ripening in 'Bluecrop' highbush blueberries. Sci. Hortic., 245, 163-170, https://doi.org/10.1016/j.scienta.2018.10.019

Ciriminna, R., Fidalgo, A., Delisi, R., Ilharco, L. M., Pagliaro, M. (2016). Pectin production and global market. Agro Food Industry HiTech., 27(5), 17-20.

Ciriminna, R., Fidalgo, A., Delisi, R., Tamburino, A., Carnaroglio, D., Cravotto, G., ..., Pagliaro, M. (2017). Controlling the degree of esterification of citrus pectin for demanding applications by selection of the source. ACS Omega, 2(11), 7991-7995. https://doi.org/10.1021/ acsomega.7b01109

Colodel, C., Bagatin, R., Tavares, T. M., Petkowicz, C. (2017). Cell wall polysaccharides from pulp and peel of cubiu: A pectin-rich fruit. Carbohydr. Polym., 174, 226-234. https://doi.org/10.1016/j.carbpol.2017.06.052
Dimopoulou, M., Alba, K., Campbell, G., Kontogiorgios, V. (2019). Pectin recovery and characterization from lemon juice waste streams. J. Sci. Food Agric., 99(44), 6191-6198. https://doi.org/10.1002/jsfa.9891

Fan, L., Zuo, S., Tan, H., Hu, J., Cheng, J., Wu, Q., Nie, S. (2020). Preventive effects of pectin with various degrees of esterification on ulcerative colitis in mice. Food Funct., 11(4), 2886-2897. https://doi.org/10.1039/C9FO03068A

Fazio, A., La Torre, C., Dalena, F., Plastina, P. (2020). Screening of glucan and pectin contents in broad bean (Vicia faba L.) pods during maturation. Eur. Food Res. Technol., 246, 333-347. https://doi.org/10.1007/ s00217-019-03347-4

Ghai, K., Gupta, P. K., Gupta, A. K. (2016). Physiochemical behaviour changes during ripening in fruits of Trewia nudiflora Linn. Perspec. Sci., 8, 596-598. https://doi. org/10.1016/j.pisc.2016.06.031

González-Soberanis, M. C., Casas, A. (2004). Traditional management and domestication of tempesquistle, Sideroxylon palmeri (Sapotaceae) in the Tehuacán-Cuicatlán Valley, Central Mexico. J. Arid. Environ., 59(2), 245258. https://doi.org/10.1016/j.jaridenv.2004.01.018

Harholt, J., Suttangkakul, A., Scheller, H. V. (2010). Biosynthesis of pectin. Plant Physiol., 153, 384-395. https:// doi.org/10.1104/pp.110.156588

Jafari, F., Khodaiyan, F., Kiani, H., Hosseini, S. S. (2017). Pectin from carrot pomace: Optimization of extraction and physicochemical properties. Carbohydr. Polym., 157, 1315-1322. https://doi.org/10.1016/j.carbpol.2016. 11.013

Kanchana, C., Wellala, D., Bi, J., Liu, X., Liu, J., Lyu, J., $\mathrm{Wu}, \mathrm{X}$. (2019). Juice related water-soluble pectin characteristics and bioaccessibility of bioactive compounds in oil and emulsion incorporated mixed juice processed by high pressure homogenization. Food Hydrocoll., 93, 56-67. https://doi.org/10.1016/j.foodhyd.2019.02.011

López-Mercado, J., Nambo, A., Toribio-Nava, M.-E., Melgoza-Sevilla, O., Cázarez-Barragán, L., Cajero-Zul, L., ..., Cardenas-Galindo, M.-G. (2018). High and low esterification degree pectins decomposition by hydrolysis and modified Maillard reactions for furfural production. Clean Technol. Envir. Policy, 20, 1413-1422. https:// doi.org/10.1007/s10098-018-1570-y

Maldonado-Culquimboz, Y., Salazar-Ocampo, S. M., Millones, Ch. C. E., Torres, M. E. V., Vásquez, C. E. R. (2010). Extracción de pectina mediante el método de hidrólisis ácida en frutos de maushan (Vasconcellea weberbaueri (Harms) V.M. Badillo) provenientes del distrito de San Miguel de Soloco, región Amazonas. Rev. 
Aporte Sant., 3(2), 177-184. https://doi.org/10.32911/ as.2010.v3.n2.437

Masmoudi, M., Besbes, S., Abbes, F., Robert, C., Paquot, M., Blecker, C., Attia, H. (2012). Pectin extraction from lemon by-product with acidified date juice: effect of extraction conditions on chemical composition of pectins. Food Bioprocess Technol., 5, 687-695.

Martín-Sánchez, M., Martín-Sánchez, M. T., Pinto, G. (2013). Lugol reactive: History of discovery and teaching applications. Educ. Quím., 24(1), 31-36. https://doi. org/10.1016/S0187-893X(13)73192-6

Mendoza-Vargas, L., Jiménez-Forero, J., Ramírez-Niño, M. (2017). Evaluation of pectin extracted enzymatically from cocoa (Theobroma cacao L.) pod husks. Rev. UDCA Act. Div. Cient., 20(1), 131-138.

Minzanova, S. T., Mironov, V. F., Arkhipova, D. M., Khabibullina, A. V., Mironova, L. G., Zakirova, Y. M., Milyukov, V. A. (2018). Biological activity and pharmacological application of pectic polysaccharides: A review. Polymers, 10(12), 1407. https://doi.org/10.3390/ polym 10121407

Mohnen, D. (2008). Pectin structure and biosynthesis. Curr. Opin. Plant Biol., 11(3), 266-277. https://doi. org/10.1016/j.pbi.2008.03.006

Muñoz-Almagro, N., Valadez-Carmona, L., Mendiola, J. A., Ibáñez, E., Villamiel, M. (2019). Structural characterisation of pectin obtained from cacao pod husk. Comparison of conventional and subcritical water extraction. Carbohydr. Polym., 217, 69-78. https://doi.org/10.1016/j. carbpol.2019.04.040

Paniagua, C., Santiago-Doménech, N., Kirby, A. R., Gunning, A. P., Morris, V. J., Quesada, M. A., ..., Mercado, J. A. (2017). Structural changes in cell wall pectins during strawberry fruit development. Plant Physiol. Biochem., 118, 55-63. https://doi.org/10.1016/j. plaphy.2017.06.001

Patil, D. A., Rasve, V. R., Ahemad, S. S., Shirsat, M. K., Manke, M. B. (2018). Phytochemical analysis of methanolic extract of Emblica officinalis leaves. World J. Pharm. Pharm. Sci., 7(11), 971-978. https://doi. org/10.20959/wjpps201811-12493

Pawar, H. A., Gavasane, A. J., Choudhary, P. D. (2018). Extraction of polysaccharide from fruits of Cordia dichotoma $\mathrm{G}$. forst using acid precipitation method and its physicochemical characterization. Int. J. Biol. Macromol., 115, 871-875. https://doi.org/10.1016/j.ijbiomac.2018.04.146

Rascón-Chu, A., Martinez-López, A. L., Carvajal-Millán, E., Martínez-Robinson, K., Campa-Mada, A. (2016). Ionic gelation of low-esterification degree pectins from immature thinned apple. Rev. Fitotec. Mex., 39(1), 1724. https://doi.org/10.35196/rfm.2016.1.17-24

Sengar, A. S., Rawson, A., Muthiah, M., Kalakandan, S. K. (2019). Comparison of different ultrasound assisted extraction techniques for pectin from tomato processing waste. Ultrason Sonochem., 61, 104812. https://doi. org/10.1016/j.ultsonch.2019.104812

Sundarraj, A. A., Ranganathan, T. V. (2017). Phytochemical screening and spectroscopy analysis of jackfruit (Artocarpus integer Thumb.) peel. Int. Res. J. Pharm., 8(9), 151-159. https://doi.org/10.7897/2230-8407.089171

Tongkham, N., Juntasalay, B., Lasunon, P., Sengkhamparn, N. (2017). Dragon fruit peel pectin: Microwaveassisted extraction and fuzzy assessment. Agric. Nat. Resour., 51(4), 262-267. https://doi.org/10.1016/j.anres.2017.04.004

Torkova, A. A., Lisitskaya, K. V., Filimonov, I. S., Glazunova, O. A., Kachalova, G. S., Golubev, V. N., Federova, T. V. (2018). Physicochemical and functional properties of Cucurbita maxima pumpkin pectin and commercial citrus and apple pectins: A comparative evaluation. PLoS ONE, 13(9), e0204261. https://doi.org/10.1371/journal. pone. 0204261

Urias-Orona, V., Rascón-Chu, A., Lizardi-Mendoza, J., Carvajal-Millán, E., Gardea, A. A., Ramírez-Wong, B. (2010). A novel pectin material: Extraction, characterization and gelling properties. Int. J. Mol. Sci., 11, 36863695. https://doi.org/10.3390/ijms11103686

Virk, B. S., Sogi, D. S. (2004). Extraction and characterization of pectin from apple (Malus pumila cv. Amri) peel waste. Int. J. Food Prop., 7(3), 693-703. https://doi. org/10.1081/JFP-200033095

Walia, M., Sharma, U., Bhushan, S., Kumar, N., Singh, B. (2013). Arabinan-type polysaccharides from industrial apple pomace waste. Chem. Nat. Compd., 49, 794-798 https://doi.org/10.1007/s10600-013-0750-6

Wang, R. S., He, X. H., Lin, H., Liang, R. H., Liang, L., ..., Liu, C. M. (2019). Solubility difference between pectic fractions from creeping fig seeds. Polymers, 11(1), 159. https://doi.org/10.3390/polym11010159

Wolf, S., Mouille, G., Pelloux, J. (2009). Homogalacturonan methyl-esterification and plant development. Mol. Plant., 2(5), 851-860. https://doi.org/10.1093/mp/ssp066 Wrolstad, R. E., Acree, T. E., Decker, E. A., Penner, M. H., Reid, D. S., Schwartz, S. J., ..., Sporns, P. (2005). Handbook of food analytical chemistry (vol. 1 and 2; pp. 735-738 and 739-744 (vol. 1)). New Jersey, UE: WileyInterscience.

Yang, J. S., Mu, T. H., Ma, M. M. (2019). Optimization of ultrasound-microwave assisted acid extraction of pectin 
from potato pulp by response surface methodology and its characterization. Food Chem., 289, 351-359. https:// doi.org/10.1016/j.foodchem.2019.03.027

Yapo, B. M. (2011). Pectin rhamnogalacturonan II: On the "small stem with four branches" in the primary cell walls of plants. Int. J. Carbohydr. Chem., ID 964521. https://doi.org/10.1155/2011/964521

Yapo, B. M., Robert, C., Etienne, I., Wathelet, B., Paquot, M. (2007). Effect of extraction conditions on the yield, purity and surface properties of sugar beet pulp pectin extracts. Food Chem., 100, 1356-1364. https://doi. org/10.1016/j.foodchem.2005.12.012

Zaitseva, O., Khudiakov, A., Sergushkina, M., Solomina, O., Polezhaeva, T. (2020). Pectins as a universal medicine. Fitoterapia, 146, 104676. https://doi.org/10.1016/j. fitote. 2020.104676 